\title{
BMJ Open Are the early predictors of long-term work absence following injury time dependent? Results from the Prospective Outcomes of Injury Study
}

\author{
Rebbecca Lilley, Gabrielle Davie, Sarah Derrett
}

To cite: Lilley R, Davie G, Derrett $S$. Are the early predictors of long-term work absence following injury time dependent? Results from the Prospective Outcomes of Injury Study. BMJ Open 2017;7:e017390. doi:10.1136/ bmjopen-2017-017390

- Prepublication history and additional material for this paper are available online. To view these files, please visit the journal online (http://dx.doi. org/10.1136/bmjopen-2017017390).

Received 1 May 2017

Revised 7 September 2017 Accepted 15 September 2017

CrossMark

Injury Prevention Research Unit, Department of Preventive and Social Medicine, Dunedin School of Medicine, University of Otago, Dunedin, New Zealand

Correspondence to

Dr Rebbecca Lilley;

rebbecca.lilley@ipru.otago.ac.nz

\section{ABSTRACT}

Objectives Few studies examine the influence of early predictors of work absence beyond 12 months following injury or the time-dependent relative importance of these factors. This study aimed to identify the most important sociodemographic, occupational, health, lifestyle and injury predictors of work absence at 12 and 24 months following injury and to examine changes in the relative importance of these over time.

Design Prospective cohort study.

Setting The Prospective Outcomes of Injury Study, New Zealand.

Participants 2626 injured New Zealand workers aged 18-64 years were identified from the Prospective Outcomes of Injury Study recruited form New Zealand's monopoly injury compensation provider injury claims register: 2092 completed the 12-month interview (80\% follow-up) and 2082 completed the 24-month interview (79\% follow-up).

Primary and secondary outcomes measures The primary outcomes of interest was absence from work at the time of the 12-month and 24-month follow-up interviews.

Results Using modified Poisson regression to estimate relative risks, important groups of workers were identified at increased risk of work absence at both 12 and 24 months: males, low-income workers, trade/manual workers, temporary employees, those reporting two or more comorbidities and those experiencing a work-related injury. Important factors unique to predicting work absence at 12 months included financial insecurity, fixed-term employment and long weekly hours worked; unique factors at 24 months included job dissatisfaction, long weekly days worked, a prior injury and sustaining an injury that was perceived to be a threat to life.

Conclusions Important early predictors of work absence at 12 or 24 months following injury are multidimensional and have a time dependent pattern. A consistent set of predictors was, however, present at both time periods that are prime for early intervention. Understanding the multidimensional, time-dependent patterns of early predictors of long-term disability is important to optimally target timely interventions to prevent long-term work disability.

\section{INTRODUCTION}

A prolonged absence from work following injury can have many detrimental effects

\section{Strengths and limitations of this study}

- Few studies examine the multidimensional influence of preinjury and injury-related predictors of work absence beyond 12 months following injury or the time-dependent relative importance of these predictors.

- Using longitudinal cohort data, we found a multidimensional set of predictors of work absence that differed at 12 and 24 months following injury.

- The strengths of the study include data collection on outcomes at multiple time points following injury independent of the time periods for measurement of exposure measures; a large sample size with acceptable follow-up to 24 months (79\%); and examination of a multidimensional range of risk factors for work absence.

- The results are sensitive to interview and item missingness; however, sensitivity analysis found this had a negligible impact on estimates of effect size.

on an individual's long-term employment and earning prospects ${ }^{12}$ and health, ${ }^{3}$ as well as substantial societal costs. ${ }^{4}$ The longer a worker is absent from the workplace following injury, the higher the likelihood that a worker will never return to work and thus the greater the individual and social impacts of injury. ${ }^{156}$ Returning to work following injury is a critical step in the rehabilitation process, making longer term evaluation of vocational outcomes of interest. The early identification of predictors of long-term chronic work absence provides opportunities for timely intervention to prevent the development of prolonged work disability minimising the consequences of injury.

In the musculoskeletal injuries literature, the relative importance of predictive factors has been demonstrated to change across the stages of development of work disability. ${ }^{78}$ The predictors of the acute phase of work disability often differ from the predictors of the chronic phase, suggesting different interventions are 
needed to address chronic long-term work disability. ${ }^{8} \mathrm{Few}$ studies investigating work participation following traumatic injury have examined the importance of changes in predictive factors with increasing time following injury; studies typically have short follow-up periods of 6 months, or less, following injury. ${ }^{9}$

A limited number of studies have examined vocational outcomes following injury from a broad population-based perspective. Previous studies have tended to focus on specific injury types, injury to specific body regions, on specific settings of injury and on injury types typically regarded as severe such as those resulting in hospitalisation. $^{7-10}$ The Prospective Outcomes of Injury Study (POIS) gives us an opportunity to examine predictors for hospitalised and non-hospitalised acute injuries and all injury settings including road, home, recreational and work. ${ }^{11}$ Furthermore, analysis of the large POIS cohort allows us to examine predictors using a broader multidimensional perspective. Our previous analyses of work absence at 3 months following injury indicated a range of sociodemographic, occupational, lifestyle and injury factors were important predictors of outcome in the short term and that future analyses should continue examining a broader range of potential predictors for work disability. ${ }^{12}$

The aim of this study is to examine the combined preinjury influences of sociodemographic, occupational, health and lifestyle factors, and the injury itself, as predictors of work absence at 12 and 24 months following injury for a cohort of New Zealand workers. The focus of this analysis is on potentially identifiable and modifiable factors measured early in the development of long-term work absence. In addition, this study will examine if the relative importance of these early predictors of work absence change with increasing time following injury in this same cohort.

\section{METHODS}

\section{Study setting}

Recruitment of the POIS cohort was via New Zealand's universal no-fault Accident Compensation Corporation (ACC) scheme. Compensation covers all injury settings, including the home, workplace and road. Eligible participants included those on the ACC entitlement claims register (indicating their injury would require more than simple acute treatment) who had: (1) sustained an injury between June 2007 and May 2009; (2) were aged between 18 and 64 years; and (3) lived in one of five regions of New Zealand. Sensitive claims, such as for victims of abuse, are excluded. The recruitment process and resulting cohort has been described in detail elsewhere. ${ }^{11} 13$

\section{Data collection and explanatory variables}

The POIS study recruited 2856 participants in the period December 2007-August 2009. ${ }^{13}$ This paper is restricted to those POIS participants who were active workforce participants prior to their injury and had completed either, or both, a 12-month and 24-month interview. Structured telephone and postal interviews collected self-reported data following injury at 3 months, with simultaneous retrospective baseline recall and 12-month and 24-month intervals following injury.

With the exception of the injury-related variables, which relate to the injury event itself, all explanatory variables examined are preinjury variables. A priori hypotheses of a relationship with work absence and/or prior identification in previous studies was the basis of selection of each explanatory variable. ${ }^{710}$ The explanatory variables examine seven dimensions:

1. sociodemographic (age, gender, income, highest qualification, occupation, relationship status, living arrangements, material standard of living, household income adequacy and financial security);

2. physical work (repetitive hand movements, heavy lifting, physical exertion, standing and painful/tiring body positions);

3. psychosocial (job strain, support, security, satisfaction, optimism, self-efficacy and prior depressive episode);

4. work organisation (number of hours and days worked per week, employment contract and multiple job holding);

5. lifestyle (alcohol consumption, smoking status, body mass index (BMI), exercise and sleep quantity);

6 . health (overall self-assessment for health, comorbidities, pain/discomfort, prior injury, prior disabling condition and work capacity);

7. injury related (work-related injury, nature and body region of injuries, intent of injury, hospital admission or at least 3 hours treatment at an emergency department within 7 days of injury, anatomical injury severity-New Injury Severity Score (NISS)), injury perceived as a threat to life, injury perceived as a threat of serious disability and access to health services).

See table 1 for more detailed information about the explanatory variables.

\section{Outcome measure}

At 12-month and 24-month interviews a single item 'Which of the following best describes your paid work situation now?' was used to ascertain work status. Participants indicating full-time and part-time work for pay were considered to be 'working', while those indicating they were receiving a benefit and/or compensation or were unemployed were considered to be 'absent from work'.

\section{Data analysis}

The relationship between work absence and preinjury and injury-related explanatory variables was examined using frequency tables, summary statistics and regression analyses.

For each time point, adjusted univariate models were created using modified Poisson regression with robust error variance to estimate relative risks. ${ }^{14}$ Age, gender, anatomical severity of injury (NISS), interview region and all 12 injury nature and body region variables were 
Table 1 Measures used in the questionnaire

\section{Factor(s)}

Age, gender, education, income, relationship status, occupation and living arrangements

Adequacy of household income Material standard of living

Financial insecurity

Repetitive hand movements, heavy lifting, painful/tiring body positions, standing and physical exertion

Job strain, job support

Job satisfaction

Self-efficacy

\section{Optimism}

Prior depressive episode

Hours and days worked per week

Type of contract

Multiple job holding

Alcohol consumption

Smoking status

Body mass index

Physical exercise

Sleep quantity

Self-assessment for health

Comorbidities

Prior injury

Prior disability

Injury nature and body region

Work capacity

Pain

Assault

Hospital admission

\section{Description of measure and source}

Single-item questions from the New Zealand Census. ${ }^{28}$

Occupation grouped into professional (major levels 1-3), semiprofessional (levels 4 and 5) and trade/manual (levels 6-9) using New Zealand Standard Classification of Occupations ${ }^{29}$

Single item regarding adequacy of total household income to meet everyday needs ${ }^{30}$ Single item rating standard of living before injury. Single item rating financial security in the next 10 years $^{26}$

Set of five single items regarding amount of time spend doing physical task ranked on 4-point Likert scale 'never' to 'all to $3 / 4$ of the time'31

Score using the Whitehall II study adaptation of Karasek's job content model ${ }^{32}$ Single item rating overall job satisfaction/dissatisfaction ${ }^{31}$

General Self-Efficacy Scale, scale from 0 to 40, dichotomised into poor (score $\leq 25$ ) and good (score $>25)^{33}$

Agreement with expectation of more good things happen than bad, dichotomised yes (agree and strongly agree) and no (strongly disagree, disagree and neutral) ${ }^{34}$

Two items from Diagnostic and Statistical Manual III on depressed mode and loss of interest or pleasure in daily activities for at least 2 weeks in the year prior ${ }^{35}$

Single items asking number of hours or days worked in main job ${ }^{31}$

Combination of two items on employment status and, for employees only, the type of employment contract ${ }^{31}$

Single item asking if work only one paying job or more than one job ${ }^{31}$

Score (0-12) identifying hazardous drinking patterns in the year prior using the brief Alcohol Use Disorders Identification Test ${ }^{36}$

Single item asking if smoke regularly.

Calculated using weight and height, categorised underweight/normal $(\leq 25)$, overweight (25-29) and obese ( $\geq 30)$

Multiple questions ascertaining how many days over a 7 -day period engaged in $15 \mathrm{~min}$ vigorous activity or 30 min moderate activity. Dichotomised into $\leq 4$ or 5-7 days a week ${ }^{37}$

Single item identifying how many nights a week usually obtain at least 7 hours' sleep Single item rating health in the 4 weeks prior to injury with 5-point Likert scale from excellent to poor $^{38}$

Single item asking if had any of a list of 21 specific chronic conditions lasting or expected to last more than 6 months ${ }^{39}$

\section{Single item regarding any prior injuries that affect participant}

Single item asking if had a health problem or condition lasting 6 months or more that caused difficulty with daily activities OR communication/socialising OR any other activity $^{28}$

12 binary $\mathrm{Y} / \mathrm{N}$ variables indicating the presence of common nature and body region combinations were created using Accident Corporation (ACC) injury diagnosis data. Variables were created for lower extremity fracture; lower extremity open wound; lower extremity superficial injury; upper extremity fracture; upper extremity open wound; upper extremity superficial injury; head, neck and intercranial injury; head and neck superficial injury; spine dislocation, sprain or strain; upper extremity dislocation, strain or sprain; lower extremity dislocation, strain or sprain; and injury to other region

Single item scale assessing working capacity prior to injury from 1 total working capacity to 0 total inability to work $^{40}$

Single item on pain or discomfort from the EuroQol-5 Dimension ${ }^{41}$

Single item regarding if injury was the result of an assault

Single item asking if admitted to hospital for day or more 
Table 1 Continued

\begin{tabular}{ll}
\hline Factor(s) & Description of measure and source \\
\hline $\begin{array}{l}\text { Anatomical severity-New Injury } \\
\text { Severity Score (NISS) }\end{array}$ & $\begin{array}{l}\text { Score created by mapping International Statistical Classification of Diseases, 10th } \\
\text { Revision, injury codes to the Abbreviated Injury Scale (AIS) with the squares of the three } \\
\text { highest AIS scores subsequently summed to form the NISS. }\end{array}$ \\
& $\begin{array}{l}\text { greater the anatomical injury severity. Scores were categorised NISS1-3, NISS4-6 and } \\
\text { NISS }>6 .\end{array}$ \\
Self-perceived threat to life & Single item rating if felt injury was a threat to life \\
Self-perceived threat of disability & $\begin{array}{l}\text { Single item rating if felt injury was threat of severe longer term disability } \\
\text { Assessing health services }\end{array}$ \\
$\begin{array}{l}\text { Single open-ended item assessing troubles getting to or contacting health services. } \\
\text { Positive and mixed responses form the 'no difficult access' group, negative response }\end{array}$ \\
'difficult access' group \\
Single item regarding if injury was sustained while at work
\end{tabular}

included in all univariate models as potential covariates. To account for the range in the timing of the 12-month and 24-month interviews after the injury event, time since injury was also included as a continuous variable in all analyses.

Any variable from the adjusted univariate models for either the 12-month or 24-month time point with a $\mathrm{p} \leq 0.2$ was then entered into a multidimensional model for each time point. A consistent variable approach was used, resulting in both the 12-month and 24-month overall multidimensional regression models including a consistent set of variables across both time points prior to stepwise Poisson regression. All multidimensional models were additionally adjusted for age, sex, region of interview, time since injury, anatomical injury severity-NISS and injury type and region with these variable entered as fixed variables. Complete case analysis was undertaken at both time periods. A sensitivity analysis was conducted by applying inverse probability weighting (IPW) to the data to account for loss to follow-up. ${ }^{15}$ Analyses were performed using STATA statistical package V.13.0 SE.

\section{RESULTS}

Of the 2626 POIS participants who were working prior to their injury, 2092 completed the 12-month interview (79\% follow-up) and 2082 completed the 24-month interview (79\% follow-up) (table 2). At the 12-month interview, $329(16 \%)$ reported being absent from work, while 304 $(15 \%)$ were absent at the 24-month interview. Reasons for work absence were reported at 24 months following injury only and were varied: predominantly the sample was absent from work due to ongoing recovery and rehabilitation $(43 \%)$ associated with the original injury event. The majority ( $82 \%$ at 12 months, $81 \%$ at 24 months) had received earnings-related compensation from the ACC scheme, indicating a period at least 7 days' absence from the workplace following injury. There was no evidence of statistically significant differences in patterns of work absence at either 12 or 24 months by receipt of earnings-related compensation; therefore, it has not been included in our analyses.
A summary of the key sociodemographic and injury characteristics of the workforce active POIS participants interviewed at 12 and 24 months is provided in supplementary appendix 1 . The two subcohorts have broadly similar distributions of sociodemographic and injury characteristics. In comparison with the baseline interviewees, the greatest loss to follow-up occurred in individuals aged 18-29years, males, non-professional occupational groups, in North Island regions (Auckland, Manukau and Gisborne), in those with less severe injuries and those receiving earnings-related compensation. In terms of loss to follow-up of participants by injury type and region at 12 months greater loss was observed for participants with lower extremity fractures and upper extremity dislocations, strains and sprains, while at 24 months greater loss

Table 2 Completed interviews and work status in workforce active participants at the 12-month and 24 month time points

\begin{tabular}{|c|c|c|}
\hline & 12 months & 24 months \\
\hline Total sample (N) & 2092 & 2082 \\
\hline Employed prior to injury (N) & 2092 & 2082 \\
\hline $\begin{array}{l}\text { Working } 3 \text { months following injury } \\
\text { (N) }\end{array}$ & 1537 & 1537 \\
\hline $\begin{array}{l}\text { Follow-up from baseline } n=2626 \\
(\%)\end{array}$ & 79 & 79 \\
\hline \multicolumn{3}{|l|}{ Work status at interview } \\
\hline Working & 1751 & 1764 \\
\hline Absent from work & 329 & 304 \\
\hline Missing & 12 & 14 \\
\hline \multicolumn{3}{|l|}{$\begin{array}{l}\text { Reasons for work } \\
\text { absence-24 months }\end{array}$} \\
\hline Not recovered yet/rehabilitation & & 132 \\
\hline Seeking employment & & 63 \\
\hline Retired early & & 27 \\
\hline Domestic reasons & & 27 \\
\hline Other (eg, volunteering) & & 22 \\
\hline Missing & & 33 \\
\hline
\end{tabular}


was observed for those sustaining upper extremity open wounds and upper extremity superficial injuries.

Most variables from the adjusted univariate modelling step (results not shown) were retained and entered into the final multivariable 12-month and 24-month models. Variables not included in the final models included multiple job holding, repetitive hand movements, sleep quantity and work capacity.

\section{Twelve months}

Table 3 presents the final multivariable model for work absence 12 months following injury. Sociodemographic characteristics predictive of increased risk of work absence included being male, those with low levels of personal income or who could not provide an estimate of their personal income, those in trade/manual occupations and those reporting financial insecurity. Variables representing relationship status, living arrangements and adequacy of household income were not retained in the final model.

Job satisfaction was the only psychosocial factor to be retained in the final model of the seven variables initially assessed. There was statistically weak evidence that workers reporting a neutral position of neither satisfaction/dissatisfaction with their job had a higher risk of work absence (adjusted relative risks (aRRs) 1.45, 95\% CI 1.00 to 2.09). Of the four physical work variables, none were retained in the final model.

Work organisational characteristics predictive of work absence included temporary or fixed term employment contracts and long ( $\geq 46$ hours per week) or part-time hours ( $\leq 30$ hours per week). Variables indicating multiple job holding and number of weekly days worked were not retained in the final model. Of the five lifestyle factors examined, only comorbidities was retained in the final model with workers having two or more comorbidities at increased risk of work absence (aRR 1.65, 95\% CI 1.24 to 2.21). Only one injury-related factor was retained in the final model: those with a work injury had a higher risk of work absence (aRR 1.52, 95\% CI 1.19 to 2.92) compared with those with a non-work injury.

\section{Twenty-four months}

Table 3 also presents the final multivariable model with aRRs of work absence 24 months following injury. Sociodemographic factors predictive of increased risk of work absence included being male (aRR 1.91, 95\% CI 1.42 to $2.57)$, those with incomes below $\$ \mathrm{NZ} 50000$, those not reporting an income (aRR 2.45, 95\% CI 1.65 to 3.66) and those with trade/manual occupation (aRR1.73, 95\% CI 1.23 to 2.45 ). Workers reporting inadequacy of household income were more likely to be working; however, the relationship was weakly statistical significant (aRR 0.80 , 95\% CI 0.62 to 1.01 ).

Workers reporting either feeling neutral (aRR 1.59, 95\% CI 1.13 to 2.22 ) or dissatisfied (aRR $1.85,95 \%$ CI 1.27 to 2.70) with their job had a higher risk of work absence. No clear relationship was apparent for physical exertion.
Of the work organisational factors examined, workers with temporary employment contracts (aRR 1.77, 95\% CI 1.28 to 2.46 ) and those working $6-7$ days per week prior to injury (aRR $1.35,95 \%$ CI 1.03 to 1.78 ) were at increased risk of work absence. Of the lifestyle factors examined, workers with two or more comorbidities were at increased likelihood of work absence (aRR 1.79, 95\% CI 1.36 to 2.35).

Prior injury (aRR 1.40, 95\% CI 1.08 to 1.80 ), injury perceived to be a threat to life (aRR 1.48, 95\% CI 1.07 to 2.04) and work-related injuries (aRR 1.53, 95\% CI 1.20 to 1.97 ) were also predictive of increased risk of work absence.

\section{Sensitivity analysis}

Complete case analysis was under taken for all models. Sensitivity analyses, using IPW, were undertaken to assess the impact of not being included in the multivariable models in comparison with the cohort's baseline interview. Overall, the relative risks obtained using IPW were slightly lower than for the analyses presented in (table 3). Exceptions to this included low income, insecure employment and part-time working hours ( $\leq 30$ hours per week) for the 12-month model, and low income, occupation, job dissatisfaction, work-related injury and perceived threat to life for the 24-month model where the relative risks were higher than the presented analysis. Only the 12-month multivariable model had items with greater than $10 \%$ change in the effect size: the aRR was lower in workers with an 'unclassified' occupation (aRR $0.83,95 \%$ CI 0.32 to 2.13 , compared with aRR1.09, 95\% CI 0.44 to 2.71 ), for those with self-employed contracts (aRR 1.18, 95\% CI 0.85 to 1.64 , compared with aRR 1.33 , 95\% CI 0.90 to 1.97 ) and higher in employers (aRR $0.57,95 \% \mathrm{CI} 0.29$ to 1.11 , compared with aRR $0.45,95 \%$ CI 0.19 to 1.06 ) and for those working $\leq 30$ hours per week (aRR1.88, 95\% CI 1.37 to 2.59 , compared with $1.65,95 \%$ CI 1.16 to 2.33 ).

\section{DISCUSSION}

In this prospective cohort study of injured New Zealand workers, we identified a number of new preinjury sociodemographic, work organisational, health and injury-related factors that are important predictors of work absence at 12 and 24 months following injury and confirmed predictors identified previously. While a time-dependent pattern of predictors of work absence was also observed, a consistent set of six predictors was identified across both time periods with only two unique predictors at 12 months and four at 24 months following injury.

Comparisons of our findings with previous injury studies examining time-dependent patterns of risk factors for work absence are limited by our study's broader population-based design, study sample and longer follow-up. Nevertheless, our findings are broadly consistent with the few studies that have previously demonstrated that the influence and relative importance of risk factors changes with increasing time since injury. ${ }^{9}$ Our study also provides 
Open Access

Table 3 Multivariable analysis of preinjury and injury-related characteristics associated with work absence modelled for 12 months and 24 months postinjury

\begin{tabular}{|c|c|c|c|c|}
\hline \multirow[b]{2}{*}{ Dimension: variable } & \multicolumn{2}{|c|}{12 months $(n=1583)$} & \multicolumn{2}{|c|}{24 months $(n=1421)$} \\
\hline & $\mathrm{aRR}^{*}$ & $95 \% \mathrm{Cl}$ & $\mathrm{aRR}^{*}$ & $95 \% \mathrm{Cl}$ \\
\hline \multicolumn{5}{|l|}{ Sociodemographic: age } \\
\hline $18-29$ & Ref & & Ref & \\
\hline 30-49 & 0.90 & 0.65 to 1.23 & 0.68 & 0.50 to 0.92 \\
\hline $50-64$ & 0.80 & 0.55 to 1.16 & 0.75 & 0.53 to 1.06 \\
\hline \multicolumn{5}{|l|}{ Sociodemographic: gender } \\
\hline Female & Ref & & Ref & \\
\hline Male & 1.40 & 1.03 to 1.90 & 1.91 & 1.42 to 2.57 \\
\hline \multicolumn{5}{|l|}{ Sociodemographic: income } \\
\hline$\geq \$ 50001$ & Ref & & Ref & \\
\hline$\$ 30000-\$ 50000$ & 1.50 & 1.05 to 2.15 & 1.74 & 1.19 to 2.53 \\
\hline$\leq \$ 30000$ & 1.80 & 1.20 to 2.69 & 1.80 & 1.18 to 2.74 \\
\hline No income given & 2.07 & 1.36 to 3.15 & 2.45 & 1.65 to 3.66 \\
\hline \multicolumn{5}{|l|}{ Sociodemographic: occupation } \\
\hline Professional & Ref & & Ref & \\
\hline Technical & 1.07 & 0.77 to 1.50 & 1.34 & 0.94 to 1.88 \\
\hline Trade/manual & 1.55 & 1.11 to 2.15 & 1.73 & 1.23 to 2.45 \\
\hline Unclassified & 1.09 & 0.44 to 2.71 & 1.54 & 0.75 to 3.19 \\
\hline \multicolumn{5}{|l|}{ Sociodemographic: income adequacy } \\
\hline Adequate & - & - & Ref & \\
\hline Inadequate & - & - & 0.80 & 0.62 to 1.01 \\
\hline \multicolumn{5}{|l|}{ Sociodemographic: financial security } \\
\hline Secure/fairly secure & Ref & & - & - \\
\hline Fairly insecure/insecure & 1.51 & 1.17 to 1.95 & - & - \\
\hline \multicolumn{5}{|l|}{ Psychosocial: job satisfaction } \\
\hline Completely/mostly satisfied & Ref & & Ref & \\
\hline Neither satisfied nor dissatisfied & 1.45 & 1.00 to 2.09 & 1.59 & 1.13 to 2.22 \\
\hline Mostly/completely dissatisfied & 1.37 & 0.88 to 2.12 & 1.85 & 1.27 to 2.70 \\
\hline \multicolumn{5}{|l|}{ Physical: exertion } \\
\hline Never & - & - & Ref & \\
\hline Occasionally half the time & - & - & 1.16 & 0.86 to 4.56 \\
\hline Three-quarters of time or greater & - & - & 0.78 & 0.55 to 1.12 \\
\hline \multicolumn{5}{|l|}{ Work organisation: hours of work } \\
\hline$\leq 30$ hours & 1.65 & 1.16 to 2.33 & & \\
\hline $31-45$ hours & Ref & & - & - \\
\hline$\geq 46$ hours & 1.65 & 1.26 to 2.17 & - & - \\
\hline \multicolumn{5}{|l|}{ Work organisation: prework days } \\
\hline$\leq 5$ days & - & - & Ref & \\
\hline 6-7 days & - & - & 1.35 & 1.03 to 1.78 \\
\hline \multicolumn{5}{|c|}{ Work organisation: employment contract } \\
\hline Employee-permanent & Ref & & Ref & \\
\hline Employee-temporary/casual & 1.68 & 1.21 to 2.34 & 1.77 & 1.28 to 2.46 \\
\hline Employee-fixed term & 2.15 & 1.34 to 3.44 & 1.40 & 0.79 to 2.48 \\
\hline Self-employed & 1.33 & 0.90 to 1.97 & 1.27 & 0.81 to 1.98 \\
\hline
\end{tabular}


Table 3 Continued

\begin{tabular}{|c|c|c|c|c|}
\hline \multirow[b]{2}{*}{ Dimension: variable } & \multicolumn{2}{|c|}{12 months ( $n=1583$ ) } & \multicolumn{2}{|c|}{24 months $(n=1421)$} \\
\hline & $\mathrm{aRR}^{\star}$ & $95 \% \mathrm{Cl}$ & aRR $^{*}$ & $95 \% \mathrm{Cl}$ \\
\hline Employer & 0.45 & 0.19 to 1.06 & 0.42 & 0.14 to 1.24 \\
\hline \multicolumn{5}{|l|}{ Lifestyle: body mass index } \\
\hline$\leq 24$ & Ref & & Ref & \\
\hline $25-29$ & 1.23 & 0.93 to 1.64 & 0.97 & 0.73 to 1.29 \\
\hline$\geq 30$ & 1.11 & 0.82 to 1.53 & 1.07 & 0.79 to 1.45 \\
\hline \multicolumn{5}{|l|}{ Health: comorbidities } \\
\hline No comorbidities & Ref & & Ref & \\
\hline One co-morbidity & 1.03 & 0.76 to 1.40 & 0.74 & 0.53 to 1.04 \\
\hline Two or more comorbidities & 1.65 & 1.24 to 2.21 & 1.79 & 1.36 to 2.35 \\
\hline \multicolumn{5}{|l|}{ Injury: work-related injury } \\
\hline No & Ref & & Ref & \\
\hline Yes & 1.52 & 1.19 to 2.92 & 1.53 & 1.20 to 1.97 \\
\hline \multicolumn{5}{|l|}{ Injury: prior injury } \\
\hline No & - & - & Ref & \\
\hline Yes & - & - & 1.40 & 1.08 to 1.80 \\
\hline \multicolumn{5}{|l|}{ Injury: threat to life } \\
\hline No & - & - & Ref & \\
\hline Yes/maybe & - & - & 1.48 & 1.07 to 2.04 \\
\hline
\end{tabular}

*Additionally adjusted for time since injury, injury type and region, interview region and anatomical injury severity-NISS. aRR, adjusted relative risk; NISS, New Injury Severity Score.

further support to the importance of considering a multidimensional set of predictors across several time points when following the development of long-term work disability to provide longitudinal insight and to detect risk factors commonly, or primarily, associated with one or another stage of the disabling process. ${ }^{7-9} 16$ As in our earlier paper examining outcomes at 3 months following injury, ${ }^{11}$ findings from this study indicate a broad range of financial, occupational, psychosocial, work organisational and health supports for employees during recovery from injury are potentially important avenues for early intervention to interrupt prolonged absence from work.

Certain domains examined in our study have had limited, if any, attention in other research examining outcomes following acute injury. ${ }^{10}$ Work organisational factors were identified in our study as important predictors of work absence. These findings point to the provision of opportunities for recovery from overdemanding work schedules (be it long working hours or weeks) in the long-term following injury as being important for returning to work. Workers with temporary employment contracts were at higher risk of work absence at both time points. Potential mechanisms for this relationship may include the poor quality employment protections and employment relationships between parties with the use of precarious temporary employment contracts, the degree to which substitute workers are available and the difficulties of realising job accommodations for temporary workers. ${ }^{16}{ }^{17}$ While the evidence for a relationship between precarious employment contracts and work absence following injury is lacking, elsewhere, temporary employment has been associated with delays in returning to work following depression-related work disability episodes. ${ }^{18}$ Financial insecurity predicted work absence at 12 months only, suggesting financial security has an important time-dependent influence on work disability in the first year following injury, possibly through feelings of anxiety generated by future economic insecurity. ${ }^{19}$ Further research confirming these newly identified risk factors and examining potential mechanisms of these for work absence following injury is warranted.

Injury-related factors displayed a time-dependent pattern. Work-related injury was predictive of work status at both time points supporting our previous findings that workers with work-related injuries had poorer vocational outcomes by 12 months following injury. ${ }^{20}$ Our findings indicate work-related injury has an important influence on the development of long-term work absence and interventions focusing on primary and secondary prevention of work-related injury would influence work absence in the long term and primary prevention of these common injuries in the first place. By 24 months, the perception of the injury as having been a threat to life and having had a prior injury emerged as important injury-related risk factors. Possible mechanisms for this relationship may lie in the psychological trauma associated with the 
event, such as through the development of post-traumatic stress disorder. Self-perception of the injury event is rarely examined in studies of work absence, and this relationship merits further investigation. Few studies examining outcomes following injury examine previous injury; however, the only other study to consider previous injury found higher odds of work disability at 1 year following back injury. ${ }^{21}$ Further studies should consider prior injury as a potential risk factor for long-term work disability.

A number of our findings support and extend previous studies findings. Our finding that income and occupation are important predictors of work absence at both 12 and 24 months following injury is consistent with a growing body of longitudinal evidence. ${ }^{8} 1022$ Differing financial incentives, commonly substituted low remuneration work skills, the physical nature of work and practical difficulties in providing work accommodations to trade/manual workers are possible income and occupational barriers to work participation. Our finding that the presence of several pre-existing comorbidities is an important health-related risk factor for work absence at both time periods extends the findings of previous studies observing comorbid conditions associated with a delayed return-to-work up to 6 months following injury. ${ }^{23}{ }^{24}$ Workers with several comorbid conditions experience an impaired health state prior to injury, and following the injury itself, this may limit a person's ability to engage with the injury rehabilitation process, or to manage their chronic conditions, resulting in difficulties maintaining work. The prevalence of multimorbidity in developed nations is increasing rapidly ${ }^{25}$; therefore, further analysis is warranted to examine the long-term influence of comorbidity on the risk of work disability following injury.

Job satisfaction emerged as the only important preinjury psychosocial factor predictive of work status at 24 months following injury. Recent evidence that job satisfaction is not predictive of return-to work following injury or musculoskeletal disorders is limited by short follow-up periods up to 12 months following injury. ${ }^{17}{ }^{26}$ Our findings suggest studies with follow-up beyond 12 months should consider job satisfaction as a possible risk factor for prolonged work absence. Psychosocial factors have been identified as predictive of work absence in other injury studies ${ }^{810}$; however, this evidence is limited by the lack of multivariable analysis and the narrow range of potential preinjury predictors and covariates examined, potentially explaining why our findings differ from others.

Finally, changes in the predictive value of risk factors over time has significant implications for the types and timing of interventions required to prevent the development of work disability. ${ }^{816}$ While our findings highlight the importance of distinguishing time-dependent predictors, we did identify a consistent set of potentially modifiable preinjury and injury-related risk factors that are present regardless of the disability phase that are prime for early intervention. Risk factors consistently identified in our current analysis at 12 and 24 months and in our previous analysis at 3 months following injury include workers with low incomes, trade/manual occupations, temporary employment contracts, overdemanding work schedules and an injury perceived to be a threat to life. ${ }^{12}$ Given our study identified few unique time-dependent risk factors, our findings suggest that interventions primarily targeting workers with these consistent preinjury and injury risk factors should be made in the first few months following injury as early interventions targeting improvements in employment status can potentially change the progression of both short-term and long-term work absence. ${ }^{27}$

This study has some limitations. First preinjury factors and baseline preinjury work status were collected through self-report at the first interview (on average 3 months following injury) and may be subject to recall bias, particularly in those variables of a subjective nature such as the psychosocial factors. The self-reported preinjury work absence measure was found to be accurate by verifying self-reported data against ACC injury claims data about paid employment, with greater than 99\% concordance. Second, use of single-item constructs for many psychosocial factors, such as optimism and job security, may be a limitation. However, good reliability and validity has been demonstrated with parsimonious measures while reducing the interview burden on participants. ${ }^{26}$ Third, the capture of all types of work absence (more commonly for disability or unemployment) could potentially explain the shift in patterns of risk factors overtime as the longer a worker is absent from work, the greater the likelihood of unemployment or redundancy. The relative proportion of officially unemployment in our work-absent participants at 12 months (15\%) and 24 months (18\%) was small and was unlikely to be the substantial driver of the time-dependent shift in risk factors that we observed. Finally, this analysis uses two slightly different groups of individuals followed up at two separate time points following the original injury using complete case analysis. While $90 \%$ of participants who completed the 12-month interview also completed the 24-month interview, this analysis is sensitive to interview missingness, as well as item missingness for those who completed 12-month and 24-month interviews. Sensitivity analyses, undertaken to assess the impact of being included in the final multivariable models in comparison with the baseline interview, found very few variables had a meaningful increase in effect size (ie, $>10 \%$ change), and only one, working part-time hours, was significant in the final 12-month multivariable model.

Our study offers a number of strengths that overcome some of the limitations of previous studies including: the collection of comprehensive preinjury information at 12 and 24 months following injury across a broad multidimensional perspective; a large sample size with acceptable follow-up to 24 months (79\%); the inclusion of non-hospitalised injured participants; the measurement of outcomes at time periods independent of the time periods for measurement of exposure measures; and combined multidimensional analysis examining a comprehensive range of risk factors for work disability. 
A further key strength is the measurement of preinjury and early-injury exposures that provide opportunity for identifying early interventions to influence long-term work disability outcomes. The use of two point-in-time measures of work participation is also a strength as it best captures long-term outcomes since follow-up occurs regardless of previous work status and of previous non-response. Finally, we have been able to examine within New Zealand's universal no-fault injury rehabilitation and compensation scheme the early predictors of longterm work disability for all injured workers, regardless of whether the injury was sustained at work or not. This is a strength as being absent from the workplace, irrespective of where the injury occurred, has substantial socioeconomic costs to individuals, employers and to society. Our findings are generalisable to those injury rehabilitation and compensation systems with similar coverage of work and non-work injury.

In conclusion, in this study, we identified a number of known and new sociodemographic, work organisational, health and injury-related factors predictive of work absence at 12 and 24 months following injury in a cohort of New Zealand workers. Our study confirmed and extended previous observations of a time-dependent pattern of predictors of work disability following injury; however, there was a consistent set of sociodemographic, work organisational, health and injury-related factors present regardless of the timing of follow-up that are prime for early intervention to prevent the development of long term work disability. Understanding the multidimensional and time-dependent patterns of predictors of long-term disability and how they may, or may not, differ by time is important if we are to develop and optimally target early interventions to reduce the significant personal and social burden and costs of long-term work disability.

Acknowledgements We are most grateful to the study participants for sharing their information with us. We thank Dr Ari Samaranayaka, Biostatistician, Department of Preventive and Social Medicine, University of Otago, for conducting the sensitivity analyses.

Contributors RL was the lead author and is guarantor of this paper. RL analysed the data. GD and SD contributed to the study design, interpretation of the results and the review and editing of the manuscript. All authors approved the submitted manuscript.

Funding This work was supported by the Health Research Council of New Zealand (2007-2013) and the Accident Compensation Corporation (2007-2010) (HRC programme grant ID 10/052).

Competing interests None declared.

Patient consent Obtained.

Ethics approval The New Zealand Multi-Region Ethics Committee granted ethical approval for this study (MEC/07/07/093). Informed consent was obtained from all participants.

Provenance and peer review Not commissioned; externally peer reviewed.

Data sharing statement We have a data sharing policy and would consider requests on a case-by-case basis. Please contact sarah.derrett@otago.ac.nz.

Open Access This is an Open Access article distributed in accordance with the Creative Commons Attribution Non Commercial (CC BY-NC 4.0) license, which permits others to distribute, remix, adapt, build upon this work non-commercially, and license their derivative works on different terms, provided the original work is properly cited and the use is non-commercial. See: http://creativecommons.org/ licenses/by-nc/4.0/

(C) Article author(s) (or their employer(s) unless otherwise stated in the text of the article) 2017. All rights reserved. No commercial use is permitted unless otherwise expressly granted.

\section{REFERENCES}

1. Crichton S, Stillman S, Hyslop D. Returning to work from injury: longitudinal evidence on employment and earnings. ILR Review 2011;64:765-85.

2. Boden LI. Occupational injury and illness meet the labour market. Ann N Y Acad Sci 2006;1076:858-70.

3. Cameron CM, Kliewer EV, Purdie DM, et al. Long term health outcomes after injury in working age adults: a systematic review. $J$ Epidemiol Community Health 2006;60:341-4.

4. O'Dea D. New Zealand estimates of the total social and economic costs of injury. For all injuries and the six priority areas. Wellington:New Zealand: Injury Prevention Strategy, 2012.

5. Hashemi L, Webster BS, Clancy EA, et al. Length of disability and cost of work-related musculoskeletal disorders of the upper extremity. J Occup Environ Med 1998;40:261-9.

6. Hashemi L, Webster BS, Clancy EA. Trends in disability duration and cost of workers' compensation low back pain claims (1988-1996). J Occup Environ Med 1998;40:1110-9.

7. Krause N, Frank JW, Dasinger LK, et al. Determinants of duration of disability and return-to-work after work-related injury and illness: challenges for future research. Am J Ind Med 2001;40:464-84.

8. Turner JA, Franklin G, Turk DC. Predictors of chronic disability in injured workers: a systematic literature synthesis. Am J Ind Med 2000;38:707-22.

9. Clay FJ, Newstead SV, Watson WL, et al. Determinants of return to work following non life threatening acute orthopaedic trauma: a prospective cohort study. J Rehabil Med 2010;42:162-9.

10. Clay FJ, Newstead SV, McClure RJ. A systematic review of early prognostic factors for return to work following acute orthopaedic trauma. Injury 2010;41:787-803.

11. Derrett S, Langley J, Hokowhitu B, et al. Prospective outcomes of injury study. Inj Prev 2009;15:e3.

12. Lilley R, Davie G, Ameratunga S, et al. Factors predicting work status 3 months after injury: results from the prospective outcomes of injury study. BMJ Open 2012;2:e000400.

13. Derrett S, Davie G, Ameratunga S, et al. Prospective outcomes of injury study: recruitment, and participant characteristics, health and disability status. Inj Prev 2011;17:415-8.

14. Zou G. A modified poisson regression approach to prospective studies with binary data. Am J Epidemiol 2004;159:702-6.

15. Seaman SR, White IR. Review of inverse probability weighting for dealing with missing data. Stat Methods Med Res 2013;22:278-95.

16. Linton SJ, Gross D, Schultz IZ, et al. Prognosis and the identification of workers risking disability: research issues and directions for future research. J Occup Rehabil 2005;15:459-74.

17. MacEachen E, Clarke J, Franche R-L, et al. Workplace-based return to work literature review group, systematic review of the qualitative literature on return to work after injury. Scand $J$ Work Environ Health 2006;32:257-69.

18. Ervasti J, Vahtera J, Virtanen $\mathrm{P}$, et al. Is temporary employment a risk factor for work disability due to depressive disorders and delayed return to work? The Finnish Public Sector Study. Scand J Work Environ Health 2014;40:343-52.

19. Ferrie JE, Shipley MJ, Stansfeld SA, et al.Future uncertainty and socioeconomic inequalities in health: the Whitehall II study. Soc Sci Med 2003;57:637-46.

20. Lilley R, Davie G, Langley J, et al. Do outcomes differ between work and non-work-related injury in a universal injury compensation system? Findings from the New Zealand Prospective Outcomes of Injury Study. BMC Public Health 2013;13:995.

21. Turner JA, Franklin G, Fulton-Kehoe D, et al. ISSLS prize winner: early predictors of chronic work disability. Spine 2008;33:2809-18.

22. Shi Q, Sinden K, MacDermid JC, et al. A systematic review of prognostic factors for return to work following work-related traumatic hand injury. J Hand Ther 2014;27:55-62.

23. Clay FJ, Newstead SV, Watson WL, et al. Bio-psychosocial determinants of persistent pain 6 months after non-life-threatening acute orthopaedic trauma. J Pain 2010;11:420-30.

24. Clay FJ, Newstead SV, Watson WL, et al. Bio-psychosocial determinants of time lost from work following non life threatening acute orthopaedic trauma. BMC Musculoskelet Disord 2010;11:6. 
25. Marengoni A, Angleman S, Melis R, et al. Aging with multimorbidity: a systematic review of the literature. Ageing Res Rev 2011;10:430-9.

26. Ferrie JE, Westerlund $\mathrm{H}$, Virtanen $\mathrm{M}$, et al. Flexible labor markets and employee health. Scand J Work Environ Health 2008;6:98-110.

27. Franche RL, Cullen K, Clarke J, et al.Workplace-based return-towork interventions: a systematic review of the quantitative literature. J Occup Rehabil 2005;15:607-31.

28. Statistics New Zealand. 2006 Census of Population and Dwellings. Wellington: Statistics New Zealand. www.stats.govt.nz. (cited 1 March 2010).

29. Statistics New Zealand. New Zealand Standard Classification of Occupations. Wellington: Statistics New Zealand, 2001.

30. Statistics New Zealand. Household Economic Survey 2006-7 printable questionnaires. Wellington: Statistics New Zealand. www. stats.govt.nz. (cited 10 Nov 2010).

31. European Foundation for the Improvement of Living and Working Conditions. Third European survey on working conditions, 2000. Luxembourg: Office for Offical Publications of the European Communities, 2001.

32. Bosma H, Peter R, Siegrist J, et al. Two alternative job stress models and the risk of coronary heart disease. Am J Public Health 1998;88:68-74.

33. Schwarzer R, Jerusalem M. Generalized Self-Efficacy scale. In: Weinman SWJ, Johnston M, eds. Measures in health psychology: A user's portfolio. Causal and control beliefs. NFER-NELSON, 1995.

34. Scheier MF, Carver CS, Bridges MW. Distinguishing optimism from neuroticism (and trait anxiety, self-mastery, and self-esteem): a reevaluation of the Life Orientation Test. J Pers Soc Psychol 1994;67:1063-78.

35. American Psychiatric Association Committee of Nomenclature and Statistics. Diagnostic andstatisical manual of mental disorder - 3rd edition DSM-3. Washington: DC: American Psychiatric Association, 1980.

36. Bradley KA, DeBenedetti AF, Volk RJ, et al. AUDIT-C as a brief screen for alcohol misuse in primary care. Alcohol Clin Exp Res 2007;31:1208-17.

37. Sport and Recreation New Zealand. The New Zealand physical acitivity questionnaires. Wellington: SPARC, 2004.

38. Ware JE, Snow KK, Kosinski M, et al. SF-36 health survey: Manual and interpretation guide. Quality Metric Inc: Lincoln, RI, 2000.

39. Ministry of Health. New Zealand Health Survey. Wellington: Ministry of Health: Wellington, 2006.

40. Lehto A-M. Efficient,more efficient, exhasted: findings of the finnish quality of work life surveys 1977-1997. Helsinki: Statistics Finland 1999.

41. EuroQol Group. EuroQol--a new facility for the measurement of health-related quality of life. Health Policy 1990; 16:199-208.

42. Fingerhut LA, Warner M. The ICD-10 injury mortality diagnosis matrix. Inj Prev 2006;12:24-9.

43. Gennarelli T, Wodzin E. The abbreviated injury scale 2005. Update 2008. Des Plaines: Association for the Advancement of Automotive Medicine, 2008. 